\title{
Molecular cloning of the aspartate 4-decarboxylase gene from Pseudomonas sp. ATCC 19121 and characterization of the bifunctional recombinant enzyme
}

\author{
Nai-Chen Wang $\cdot$ Chia-Yin Lee
}

Received: 27 February 2006 /Revised: 18 April 2006 / Accepted: 19 April 2006 / Published online: 8 June 2006

(C) Springer-Verlag 2006

\begin{abstract}
L-Aspartate 4-decarboxylase (Asd) is a major enzyme used in the industrial production of L-alanine. Its gene was cloned from Pseudomonas sp. ATCC 19121 and characterized in the present study. The 1,593-bp asd encodes a protein with a molecular mass of 59,243 Da. The Asd from this Pseudomonas strain was considerably homologous to other Asds and aminotransferases, and has evolved independently of these enzymes from grampositive microbes. Productivity rate of the C-terminal Histagged fusion Asd was at $33 \mathrm{mg} / \mathrm{l}$ of Escherichia coli transformant culture. The kinetic parameters $K_{\mathrm{m}}$ and $V_{\max }$ of the fusion protein were $11.50 \mathrm{mM}$ and $0.11 \mathrm{mM} / \mathrm{min}$, respectively. Gel filtration analysis demonstrated that Asd is a dodecamer at $\mathrm{pH} 5.0$ while $4.4 \%$ of the recombinant protein dissociated into dimer when the $\mathrm{pH}$ was increased to 7.0. Asd exhibited its maximum activity at $\mathrm{pH} 5.0$ and specific activity of $280 \mathrm{U} / \mathrm{mg}$, and remained stable over a broad range of $\mathrm{pH}$. The optimum temperature for Asd reaction was $45{ }^{\circ} \mathrm{C}$, and $92 \%$ of the activity remained when the enzyme was incubated at $40{ }^{\circ} \mathrm{C}$ for $40 \mathrm{~min}$. This enzyme did not have any preferred divalent cation for catalysis. The recombinant Asd also exhibited aminotransferase activity when D,L-Asp, L-Glu, L-Gln, and L-Ala were utilized as substrates. However, the decarboxylation activity of L-aspartate was 2,477 times higher than its aminotransferase activity. The present study is the first investigation on the important biochemical properties of the purified recombinant Asd.
\end{abstract}

N.-C. Wang $\cdot$ C.-Y. Lee $(\bowtie)$

Graduate Institute of Agricultural Chemistry,

National Taiwan University,

No. 1, Sec. 4, Roosevelt Rd.,

Taipei 10617 Taiwan, Republic of China

e-mail: m477@ntu.edu.tw

\section{Introduction}

L-Aspartate 4-decarboxylase (Asd; EC 4.1.1.12), a pyridoxal 5'-phosphate (PLP)-dependent enzyme, catalyzes the $\beta$-decarboxylation of L-aspartate to L-alanine and $\mathrm{CO}_{2}$. This enzyme is markedly activated by $\alpha$-keto acids (Nishimura et al. 1962) and considered as bifunctional because a low-level nonspecific L-amino acid transamination activity was demonstrated in Asd from Alcaligenes faecalis (Novogrodsky et al. 1963). Both transamination and $\beta$-decarboxylation involve the same quinonoid intermediate which, later on, diverge in the subsequent steps of the individual reactions (Dunathan 1966). To find amino acid residues of Asd directing the process of catalysis would be interesting. The decarboxylases occur in mammals and various microorganisms such as bacteria, actinomycetes, and fungi (Crawford 1958; Wilson and Kornberg 1963; Chibata et al. 1965; Bowers et al. 1970; Rathod and Fellman 1985; El-Rahmany 1994). But up to now, only three asd genes have been cloned from microorganisms (Rozzell 1991; Chen et al. 2000; Abe et al. 2002). In addition, more than 300 bacterial genomes were already completely sequenced and asd was only found in probably 6 of them. This prompted us to clone another asd from strains with a decarboxylase activity to identify the important amino acid residues in the $\beta$-decarboxylation reaction.

As an amino acid infusion and food additive component, L-alanine is usually produced by an enzymatic method. Chibata et al. (1965) initially applied Asd for the production of L-alanine using immobilized Pseudomonas dacunhae cells. Recently, we constructed an expressing strain to more efficiently obtain a large amount of Histagged Asd (Chen et al. 2000). Even though the general biochemical investigations of the bacterial Asd were already 
undertaken since the $1950 \mathrm{~s}$, no detailed characterization has ever been done on His-tagged Asd that was designed for rapid protein purification. In the present study, an asd gene with exceptionally high GC content was cloned from Pseudomonas sp. ATCC 19121, which had been identified as an alanine-producing strain. The corresponding protein was highly produced as the His-tagged recombinant Asd in Escherichia coli. A number of biochemical and biophysical properties of the purified recombinant enzyme were investigated for the first time in the present work and, thus, facilitate further molecular studies and its biotechnological applications.

\section{Materials and methods}

Bacterial strains, plasmids, and culture conditions

Pseudomonas sp. ATCC 19121 was purchased from the American Type Culture Collection (Rockville, USA). Escherichia coli XL1-Blue and E. coli BL21(DE3)pLysS (Novagen) grown at $37{ }^{\circ} \mathrm{C}$ overnight in Luria-Bertani (LB) medium were used as hosts for cloning and expression of the gene. When necessary, ampicillin and chloramphenicol were added to a final concentration of 100 and $34 \mu \mathrm{g} / \mathrm{ml}$, respectively. Plasmids pGEM-T Easy (Promega) and pBluescript II KS $(+)$ (Stratagene) were used as gene cloning vectors, and the pET-21b (Novagen) was used to express the gene.

DNA manipulations and sequence analysis

Genomic DNA of Pseudomonas sp. ATCC 19121 was extracted using the Blood \& Tissue Genomic kit (Viogene, Taiwan). Restriction enzymes (New England Biolabs) and T4 DNA ligase (Invitrogen) were used according to the instructions of the suppliers. General DNA manipulation techniques used in this study were applied as described by Sambrook et al. (1989). Both strands of the insert of pBKasdP-A9 were sequenced to confirm its identity. The nucleotide sequences were determined using an ABI Prism 3770 DNA sequencer (Perkin Elmer). The BLAST (Altschul et al. 1997) was used for protein homology search, and the EMBOSS-Align (needle) program on the EMBL-EBI website was used to determine nucleotide identity. ClustalX (Thompson et al. 1997) was used for multiple sequence alignment. A phylogenetic tree was constructed by the neighbor-joining (NJ) method (Saitou and Nei 1987) using the PHYLIP 3.5 program.

\section{Cloning of the Pseudomonas sp. ATCC 19121 asd gene}

A degenerate sense primer, 5'-GGBGTBCGNTTCCTB GGBAAGWC-3' (N, any base; $\mathrm{B}, \mathrm{C}$ or $\mathrm{G}$ or $\mathrm{T}$; $\mathrm{W}, \mathrm{A}$ or T), and a degenerate antisense primer, $5^{\prime}$-CCVAGNCGC CAVCCSGT-3' (V, A or C or G; S, C or G), were designed based on the Asd consensus sequences from $P$. dacunhae and A. faecalis (Chen et al. 2000). The DNA fragment, amplified by polymerase chain reaction (PCR), was cloned into pGEM-T Easy vector to maintain and analyze the nucleotide sequence. When used as a probe, the $A v a \mathrm{I}-B g l \mathrm{II}$ fragment $(252 \mathrm{bp})$ was labeled with DIG using a DNA labeling kit (Roche), following the protocol of the supplier. After Southern blot analysis, the 8- to 10-kb fragments of the genomic DNA from Pseudomonas sp. ATCC 19121 were collected and inserted into the multiple cloning site of pBluescript II KS(+). The ligation mixture was transformed into E. coli XL1-Blue, and white colonies were screened by hybridization using the DIG-labeled probe. The plasmid isolated from a positive clone was called pBK-asdP-A9.

Construction of Asd expression vector

Pseudomonas sp. ATCC 19121 Asd was expressed in E. coli using a $\mathrm{T} 7$ expression system according to the manufacturer's instructions (Novagen). The asd gene was amplified by PCR using an N-terminal primer, 5'-ATCA CAAGGAGCTCCGCAAT-3', containing a $\mathrm{SacI}$ site and a C-terminal primer, 5'-AGAAGCTTCTCCTTGCC CAGCGC-3', including a HindIII site and the pBK-asdPA9 as the template. The amplified DNA fragment was digested by SacI and HindIII, and then cloned into an expression vector $\mathrm{pET}-21 \mathrm{~b}$ to produce hexahistidine-tagged Asd. The resultant expression vector was named pES1, in which the asd sequence was verified.

Production and purification of recombinant Asd

After pES1 was transformed into E. coli BL21(DE3)pLysS cells, a single colony was inoculated into $5 \mathrm{ml}$ LB media containing ampicillin and chloramphenicol. The overnight culture $(2 \mathrm{ml})$ was transferred to $200 \mathrm{ml}$ of the same media and cultured at $37^{\circ} \mathrm{C}$ with shaking. The expression of the asd gene was induced by adding $\beta$-isopropyl-D-thiogalactoside (IPTG) at a final concentration of $0.4 \mathrm{mM}$ to the cultures that had reached a cell density with an $\mathrm{A}_{600}$ of 0.5 1. The temperature was then reduced to $30^{\circ} \mathrm{C}$. Cells were harvested after $5 \mathrm{~h}$, rinsed with $50 \mathrm{mM}$ Na-phosphate buffer (pH 7.4), resuspended in $20 \mathrm{mM}$ Na-phosphate buffer (pH 7.4) with $0.5 \mathrm{M} \mathrm{NaCl}$, and lysed by sonication. The His-tagged Asd was purified to homogeneity using a prepacked fast liquid chromatography (Amersham Pharmacia ÄKTA system) HiTrap chelating column, according to manufacturer's instructions. The recombinant His-tagged Asd was finally eluted with a buffer that contained 360$435 \mathrm{mM}$ imidazole, and was then analyzed by sodium dodecyl sulfate-polyacrylamide gel electrophoresis (SDS- 
PAGE), which was performed in $0.375 \mathrm{M}$ Tris- $\mathrm{HCl}$ buffer (pH 8.8) with $0.1 \%$ SDS on a $10 \%$ gel, following the method of Laemmli (1970).

Estimation of Asd activity and protein content

Asd activity was determined by measuring the amounts of L-alanine appearance. One unit of decarboxylase activity was defined as the amount of enzyme that produced $1 \mu \mathrm{mol} / \mathrm{min}$ of L-alanine at $37{ }^{\circ} \mathrm{C}$. The standard Asd activity assay was performed by adding 10-50 nM Asd to the reaction mixture that contained $0.5 \mathrm{mM}$ PLP, $1 \mathrm{mM} \alpha$ ketoglutarate, and 0.1 M K-phosphate buffer ( $\mathrm{pH}$ 6.8). After preincubation at $37{ }^{\circ} \mathrm{C}$ for $40 \mathrm{~min}, 40 \mathrm{mM}$ L-aspartate (neutralized) was added to trigger the reaction, which was subsequently terminated by boiling. The resulting L-alanine was quantified by three independent methods: (a) A coupled L-amino acid oxidase assay was used as described by Rozzell (1991). (b) An OPA-derivatized high performance liquid chromatography (HPLC) analysis: Reaction products $(50 \mu \mathrm{l}$ reaction mixture) were derivatized by $200 \mu \mathrm{l} o$-phthaldialdehyde (OPA) reagent solution (Sigma) for 2 min. Analysis using a HPLC Hydrocell RP 10S $150 \times 4.6 \mathrm{~mm}$ column (BioChrom Labs, Terre Haute, US), with a linear $14 \mathrm{~min}$ gradient of acetonitrile/water mixture (95:5), from 0 to $80 \%$, with $0.1 \%$ TFA (trifluoroacetic acid), was monitored at $333 \mathrm{~nm}$ by a Photodiode Array Detector (Waters). (c) An AccQ-derivatized HPLC analysis: One quarter volume of $10 \% 5$-sulfosalicylic acid was added to precipitate the protein, and the cool-treated and centrifuged mixture was then filtered through a $0.22-\mu \mathrm{m}$ filter. Amino acids were derivatized by AccQ (6-aminoquinolyl- $N$-hydroxysuccinimidyl carbamate; Waters) reagent, and HPLC separations were performed on a Symmetry C18 (5 $\mathrm{m}, 250 \times 4.6 \mathrm{~mm}$; Waters) column with fluorescence detection. The protein concentration was estimated as described by Bradford (1976) using the Bio-Rad protein assay with bovine serum albumin as the standard.

\section{Biochemical investigations}

The kinetics of the recombinant Asd were analyzed in $10 \mathrm{mM}$ K-phosphate buffer ( $\mathrm{pH}$ 6.8), containing $0.2 \mathrm{mM}$ PLP and $1 \mathrm{mM} \alpha$-ketoglutarate at $37{ }^{\circ} \mathrm{C}$ for $60 \mathrm{~min}$; then, a coupled L-amino acid oxidase reaction was performed with color development for $10 \mathrm{~min}$. The amounts of L-alanine were estimated by $\mathrm{OD}_{520}$ with 0-14 mM L-alanine solution as standard (method a).

Enzyme assays were conducted in the standard reaction mixture for $10 \mathrm{~min}$ at various temperatures to determine the effect of temperature on Asd activity. A thermostability experiment on Asd was performed by incubating $2.5 \mu \mathrm{g}$ enzyme samples in $0.1 \mathrm{M}$ phosphate buffer $(\mathrm{pH} 6.8)$ at temperatures between 30 and $60^{\circ} \mathrm{C}$ for 10 to $60 \mathrm{~min}$. After incubation, the residual activity was determined using the standard activity assay, and L-alanine was quantified by method a.

The effect of $\mathrm{pH}$ on Asd activity was investigated at $37^{\circ} \mathrm{C}$ in $75 \mathrm{mM}$ citrate buffer ( $\mathrm{pH} 3.0-5.0$ ), acetate buffer (4.05.5), phosphate buffer (6.0-7.5) and Tris buffer (7.5-9.0). The purified enzyme was maintained at $4{ }^{\circ} \mathrm{C}$ for 1 day in various buffers to measure its $\mathrm{pH}$ stability. The residual activity was analyzed using an HPLC Hydrocell column (method b).

In the examination of the effect of metal ions on Asd, purified active fractions were pooled and dialyzed against $50 \mathrm{mM}$ acetate buffer (pH 5.0) with $10 \mathrm{mM}$ EDTA for $18 \mathrm{~h}$ with one buffer change, and then dialyzed against metalion-free $50 \mathrm{mM}$ acetate buffer $(\mathrm{pH} \mathrm{5.0)}$ ) for $24 \mathrm{~h}$ with three buffer changes to elucidate the effect of chemical reagents on the enzyme activity. The dialyzed enzyme was incubated for 40 min with various metal ions at $37{ }^{\circ} \mathrm{C}$ in $100 \mathrm{mM}$ acetate buffer ( $\mathrm{pH}$ 5.0). The decarboxylation reaction was performed for $20 \mathrm{~min}$ by adding $25 \mathrm{mM} \mathrm{L}$-aspartate, and alanine was subsequently quantified by method $b$.

Aminotransferase assays

Variable amino acids (D-alanine, D-aspartate, D-cysteine, and $20 \mathrm{~L}$-amino acids present in proteins except glycine) and $3 \alpha$-keto acids ( $\alpha$-ketoglutarate, oxaloacetate, and pyruvate) were used to investigate the transamination activity of Asd. The purified enzyme was added to $35 \mathrm{nM}$ in $0.3 \mathrm{M}$ acetate buffer ( $\mathrm{pH}$ 5.0) that contained 0.5 mM PLP and $40 \mathrm{mM} \alpha$-keto acid. After preincubation at $37{ }^{\circ} \mathrm{C}$ for $40 \mathrm{~min}, 40 \mathrm{mM}$ L-amino acid was added to start the reaction, then followed by boiling to stop it. Products were analyzed using detection method c. One unit of aminotransferase was defined as the amount of enzyme that catalyzes the formation of $1 \mu \mathrm{mol}$ of the product (glutamate, aspartate, or alanine) per minute.

Gel filtration analysis

The purified recombinant Asd $(35 \mu \mathrm{g})$ was eluted at $1 \mathrm{ml} /$ min with $50 \mathrm{mM}$ acetate buffer $(\mathrm{pH} 5.0)$ or $50 \mathrm{mM}$ phosphate buffer ( $\mathrm{pH} 6.0$ or 7.0) on a TSK G3000SW column $(7.5 \mathrm{~mm}$ ID $\times 30.0 \mathrm{~cm}$; Tosoh) and recorded by an online UV detector. The column was calibrated using the Gel Filtration Standard (Bio-Rad) over a molecular mass range of $1.35-670 \mathrm{kDa}$. Asd was also eluted by fast protein liquid chromatography (FPLC) using a HiPrep 16/60 Sephacryl S-300 HR column (Amersham Pharmacia) to confirm the elution profile and the molecular weight of proteins in major peaks with the same buffer containing $0.15 \mathrm{M} \mathrm{NaCl}$. The protein standards (MW-GF-1000), 
Table 1 Comparison of Pseudomonas sp. ATCC 19121 Asd with Asd-like sequences from other species

\begin{tabular}{|c|c|c|c|c|}
\hline Species & Accession & $\begin{array}{l}\text { Nucleotide } \\
\text { identity (\%) }\end{array}$ & $\begin{array}{l}\text { Amino acid } \\
\text { identity (\%) }\end{array}$ & $\begin{array}{l}\text { Number of amino } \\
\text { acids }\end{array}$ \\
\hline \multicolumn{5}{|l|}{ Aspartate 4-decarboxylase: } \\
\hline Pseudomonas sp. & AAQ07948 & $(100)$ & $(100)$ & 531 \\
\hline Alcaligenes faecalis & AAK58507 & 77.4 & 85 & 533 \\
\hline Pseudomonas dacunhae & BAC65229 & 78.0 & 84 & 533 \\
\hline Zymomonas mobilis & AAV90306 & 65.3 & 68 & 530 \\
\hline Ralstonia metallidurans & ZP_00597251 & 64.1 & 61 & 538 \\
\hline Bacteroides fragilis $\mathrm{YCH} 46$ & BAD48268 & 54.5 & 46 & 548 \\
\hline Bacteroides fragilis NCTC 9343 & CAH07159 & 54.6 & 46 & 548 \\
\hline Bacteroides thetaiotaomicron & AAO75842 & 54.1 & 45 & 557 \\
\hline Clostridium perfringens & $\mathrm{BAB} 80047^{\mathrm{a}}$ & 41.3 & 42 & 528 \\
\hline Enterococcus faecalis & AAO80840 & 43.3 & 42 & 536 \\
\hline Tetragenococcus halophila & BAB92080 & 48.9 & 38 & 532 \\
\hline Lactobacillus sakei & YP_394920 & 49.9 & 37 & 535 \\
\hline \multicolumn{5}{|l|}{ Aminotransferase } \\
\hline Ralstonia eutropha & AAZ62070 & 68.1 & 62 & 541 \\
\hline Ralstonia eutropha & ZP_00168540 & 67.7 & 63 & 536 \\
\hline Burkholderia fungorum & ZP_00282851 & 62.0 & 60 & 554 \\
\hline Burkholderia dolosa & ZP_00982909 & 64.1 & 58 & 546 \\
\hline Vibrio splendidus & ZP_00990937 & 57.0 & 50 & 532 \\
\hline Clostridium perfringens & BAB80707 & 48.0 & 44 & 540 \\
\hline Clostridium beijerincki & ZP_00910857 & 49.2 & 45 & 545 \\
\hline Lactobacillus casei & ZP_00386474 & 54.6 & 44 & 527 \\
\hline Lactobacillus acidophilus & AAV43507 & 46.2 & 39 & 532 \\
\hline
\end{tabular}

${ }^{\mathrm{a}}$ Hypothetic protein

ranging from 29 to $2,000 \mathrm{kDa}$, used in the FPLC analysis were obtained from Simga.

Generation of polyclonal anti-Asd antisera and Western blot analysis

His-tagged recombinant Asd was affinity-purified on a nickel chelate column followed by preparative gel electrophoresis. The gel-purified Asd was then injected into a rabbit to raise antibodies. For Western analysis, eluted fractions were first collected and concentrated by microconcentrators (Nanosep 10K, Pall Filtron). Proteins quantified as $0.5 \mu \mathrm{g}$ were denatured by boiling in SDS sample buffer and then resolved by $12 \%$ SDS-PAGE, then transblotted onto polyvinylidene fluoride (PVDF) membranes (Millipore). The membrane was blocked in $12 \mathrm{mM}$ phosphate buffer ( $\mathrm{pH} 7.4)$ containing $0.8 \%(w / v) \mathrm{NaCl}$, $0.02 \%(w / v) \mathrm{KCl}$ (PBS buffer), and $5 \%(w / v)$ skim milk for overnight incubation at $4{ }^{\circ} \mathrm{C}$, and then probed with the rabbit anti-Asd serum for $1 \mathrm{~h}$ at room temperature. The membrane was washed three times, 15 min each time, with PBS buffer containing $0.1 \%(v / v)$ Tween 20, and then incubated for $1 \mathrm{~h}$ with alkaline phosphatase conjugated goat anti-rabbit IgG (Sigma). The immunocomplex was visualized by a colorimetric detection system using the BCIP/NBT substrate from Sigma.
Nucleotide sequence accession number

The complete nucleotide sequence reported in this paper has been deposited in the NCBI nucleotide sequence database under accession number AF506011.

\section{Results}

Cloning and sequence analysis of the Pseudomonas sp. ATCC 19121 asd gene

After screening the NotI-digested Pseudomonas sp. ATCC 19121 genomic library using the 252 bp probe as described in "Materials and methods" section, one positive clone was identified as having the asd gene. Sequencing of the fragment cloned in $\mathrm{pBK}-a s d P$-A9 revealed a nucleotide sequence of $8.8 \mathrm{~kb}$ and includes six open reading frames (ORF) transcribed in the same direction. Functions of the ORFs were predicted for proteins in the database. A putative membrane protein-coding region (ORF2), which encoded a polypeptide with 470 amino acids, was found upstream of the asd (ORF3). The Shine-Dalgarno sequence (AGGAGA) was found ahead of both ORF2 and ORF3, and the intergenic noncoding region between them was $55 \mathrm{bp}$. In the cloned $8.8-\mathrm{kb}$ fragment, two putative 
Fig. 1 Unrooted phylogenetic tree based on gene sequences of Asds and homologous proteins using NJ method to show the evolutionary relationships. Sequences were retrieved from GenBank according to the accession number of proteins listed in Table 1. Two branches with only Asds were oval-circled with solid line, and enzymes from gram-positive microorganisms were oval-circled with dotted line

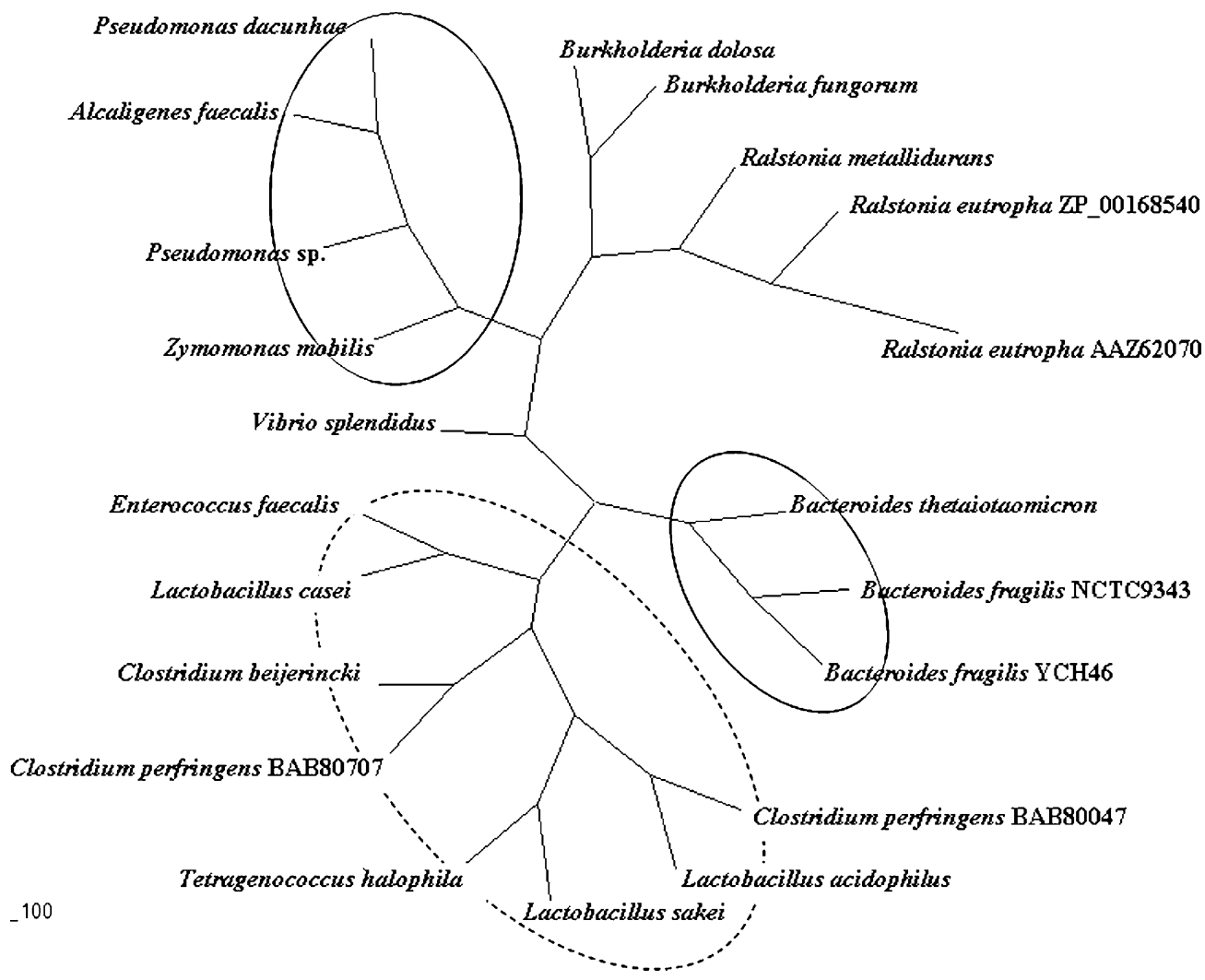

promoters were found upstream of the asd. One was about $650 \mathrm{bp}$ upstream of the ORF2, while the other one located in the ORF2 was approximately 1,250 bp upstream of the asd. Five ORFs were simultaneously identified for the antisense sequence of the $8.8-\mathrm{kb}$ insert. However, no significant similarity was found from among the deduced proteins during the databank search.

The asd contained 1,593 bp ORF and encoded a 531amino-acid Asd with a theoretical molecular mass of 59,243 Da for each subunit. The estimated isoelectric point of the translated protein was 5.62. A putative stem-loop structure was found $116 \mathrm{bp}$ downstream of the stop codon (TAG). The GC content of the cloned asd was $65.4 \%$. This is $9.4 \%$ higher than that of the asd from $P$. dacunhae CCRC 12623, and is the highest from among the asds in the databank.

Table 1 reveals that the Pseudomonas sp. cloned asd is $77-78 \%$ identical to the asd genes from $P$. dacunhae and A. faecalis. The deduced Asd protein from Pseudomonas sp. ATCC 19121 shares $45-46 \%$ of identity with the Asds from Bacteroides and 37-42\% of identity with those from gram-positive bacteria. When compared with the putative aminotransferases, the Asd exhibits 39-63\% of identity with these extraordinarily long aminotransferases.

We further investigated these similarities using the phylogenetic analysis based on DNA sequences of the relative Asds and aminotransferases. The resultant neighbor-joining tree clustered most of the Asds in two independent branches (Fig. 1). The asd sequences of Pseudomonas and Alcaligenes were apparently separate from those of the gram-positive microorganisms whose branches were interrelated with the putative Asd and aminotransferases. When compared with the Asd protein sequences, all those listed in Fig. 2 include an aminotransferase class-I PLP attachment site since all such sequences were PLP-dependent enzymes. There were 98 fully conserved amino acid residues from the Asds (indicated as stars in Fig. 2). Most of the residues were also conserved when compared with the putative aminotransferases.

Expression and purification of the recombinant Asd

Plasmid pES1, with codons for the His-tag at the $3^{\prime}$ end of the asd gene, was constructed and expressed in E. coli BL21(DE3)pLysS under the control of the T7 promoter. The recombinant Asd was purified from cell lysates by nickel affinity chromatography and yielded of $3.3 \mathrm{mg}$ of enzyme protein for every $100 \mathrm{ml}$ of culture broth. The specific activity of the homogeneously purified Asd was $280 \mathrm{U} / \mathrm{mg}$ at $\mathrm{pH} 5.0\left(37^{\circ} \mathrm{C}\right)$.

Asd productivity was examined by SDS-PAGE (Fig. 3). The molecular mass of the major signal of the $63-\mathrm{kDa}$ protein is in agreement with the molecular weight of 62,657 Da deduced from the recombinant asd. Under native conditions, gel-filtration chromatography of the purified recombinant Asd was conducted at $\mathrm{pH} 5.0$ in 


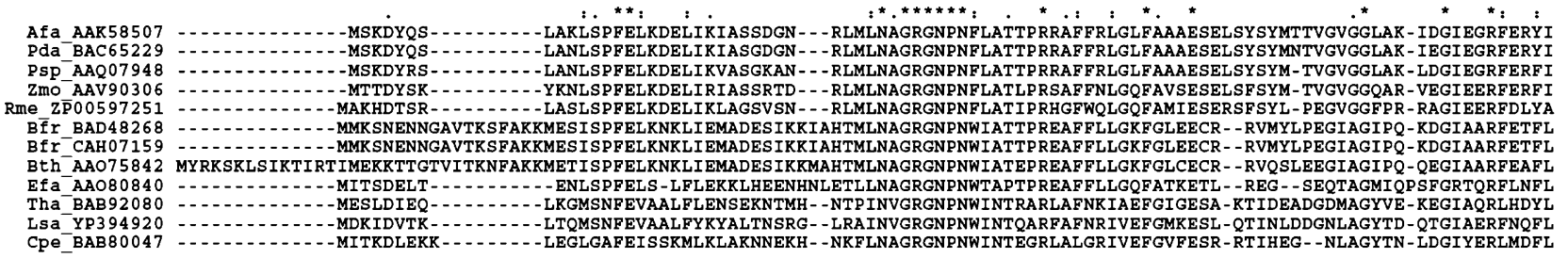

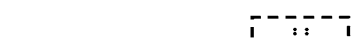

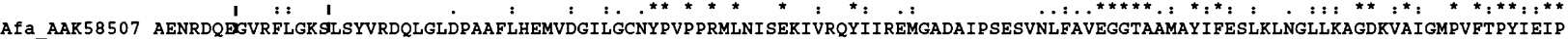
Pda-BAC65229 AENRDQDGVRFLGKSLSYVRDQLGLDPAAFLHEMVDGILGCNYPVPPRMLNISERIVRQYIIREMGADAIPSESVNLFAVEGGTAAMAY IFESMKVNGLLKAGDKVAI GMPVFTPYIEIP PSP_AAQ07948 AEHRDQEGVVEL_GKSLSYYVRDQLGLDPAAFLHEMVDGILGCNYPVPPRMLTVSEQIVRQYIVREMAGGAVPPESVDLFAVEGGTAAMAY IFESLRI SGLLKAGDKVAI GMPVFTPYIEIP ZMO AAV90306 SENRHKAGIFFLGRALSYVRDQLGLSASQFLHEMVEGILGCNYPTPPRMLSLSEQIVGQYVLREMVGSDLPTDSTDFFATEGGTAAMAYIFNSLKQNNLIKKGDKVAI GMPIFSPYIEIP Rme_ZP00597251 RVHKDVPGVKFLTGAVSYVRDQLGLDGGDFLYEMCEGILACNYPVPDRMLRLSERIVKQYIRKEMIGAHPFLGDFDLYAVEGGTAAMTYLFNSLKVNHLLNPGDTIALGMPIFTPYIEIP

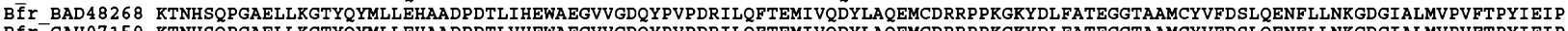
${ }_{B t h}{ }^{-}$AAO75842 2 KENEREAGARLLKETYNYMLMEHAADPDRLVHEWAESVIGDQYPVPDRILHFTELIVQDYLAQEMCDRRPPKGTFDLFATEGGTAAMCYVFDSLQENFLLNQGDSIALMI PVFTPYIEIP Efa-AAO80840 AENPSK-GATFLQEIWTAEHNYFGMDKEMWLDAMLDYVIGDNYPNPVRCLKACEQPIKAYLNQELFSSEAQP--FDIFAVEGGTAGICYLFDTLANNYLLEKGDRIALLLPTFAPYLEIP Tha BAB92080 DA--NDKTDKFILDFLAYTENNMHLNODDLVHEFVDGAI GNHYPVPSRSLVNVEKILNKYLEVSLYNGEKLADHTNVFPTEGGTAAMVYLFNELKISHILEAGDTIAINTPIFTPYLOIP

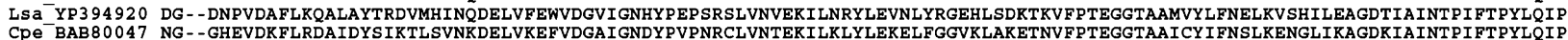

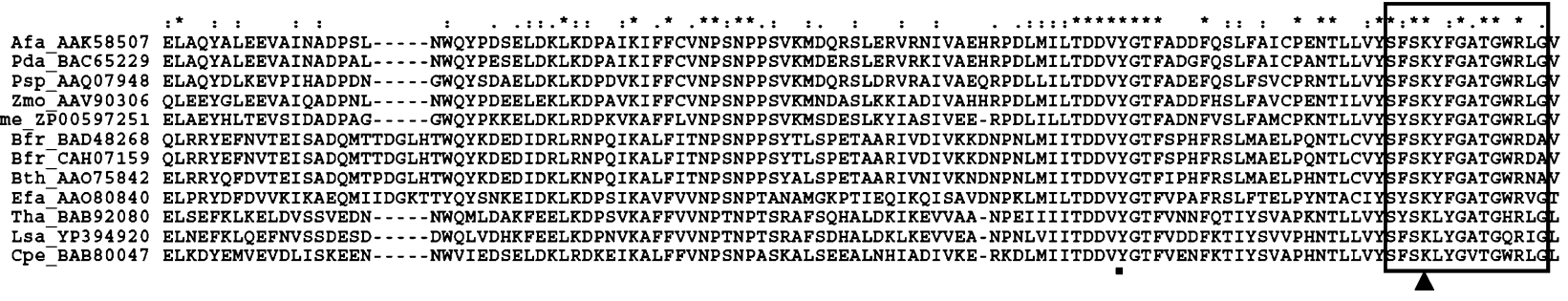

Afa_AAK 58507 VAAHQQNVFLALDKLQESE- - KVALDHRYRSLLPDVRSLKFIDRLVADSRAVALNHTAGLSTPQQVQMALFSLFALMDEAD--EYKHTLKQLIRRRETTLYRELGMPPLR-DENAVDY

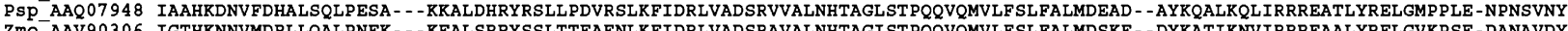

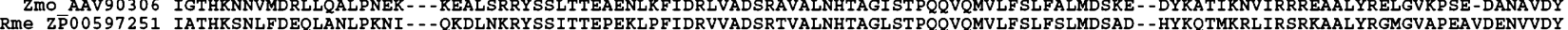
- ZPO0597251 IATHKSNLFDEQLANLPKNI---QRDLNKRYSSITTEPEKLPFIDRVVADSRTVALNHTAGLSTPQQVQMVLFSLFSLMDSAD - -HYKQTMKRLIRSRRAALYRGMGVAPEAVDENVVDY BfI_BAD48268 IALHEENIFDRMIAHLPEEQ- - - KTILNKRYSSLTLTPEKLKFIDRLVADSRQVALNHTAGLSLPQQTQMSLFASFAILDKEN - - RYKNKMQEI IRRRLKALWDNTGFSLVD - DPLRVGY BIr CAH 7 159 IALHEENIFDRMIAHLPEEQ- - - KT ILNKRYSSLTLTPEKLKFIDRMVADSRQVALNHTAGLSLPQQTQMSLFASFA ILDKEN - -RYKNKMQEI IRRRLKALWDNTGFSLVD-DPLRVGY Ef - AA080840 IAVSOENIFDOLLRELPVAR - - KMELOARYATLNADTSOINFISRLVADSRDIALNHAAGLSSIOOAMMALFSLYYLLRDGQ - - AYKDEVMDICHTRERLLFRTLGIEEPL - ASLNTAY Tha ${ }^{-}$BAB 92080 IAAHEDNVFDEI IAKRTAENAAI REEFEKRYSLVVANPLDMKFIDRTVADSREIGLYHTAGLST PQQVLMALFSLTNLIHEGEKDPYIEASKKVVDVRYNTFWKSMGIEGDH - SAEKAEY LSa-YP394920 IAMHDDNIFDKLIEEMTAEDPVIREAFRKRYSYVTNKPHEMSFIDRTVADSRNIGLYHAAGLSTPQQITMALFSLTNLIYEGREDPYVTASKEIVSHRYKAFWESLGLVVKT - TEENAEY
CPE_BAB80047 IAANENNVFDELISKLPEEK - - - LQDLDKRYGLVTFEPRKFKFIERIVADSRSVGLYHTSGLSTPQQIQMALFALTSLITKGR-DPYIESSKNLVRERYHDLCNTLGIKEDD-SRENAKY

Fig. 2 Multiple alignment of deduced amino acid sequences of Asds and putative Asds. Strains with accession numbers are illustrated as in Table 1. Identical amino-acid residues and conservative substitutions are marked as stars and dots, respectively. Residues symbolized in black boxes were supposed to be the three points mentioned by Graber et al. (1999). The triangularmark represents the lysine residue forming Schiff base with PLP during catalyzation. The boxed conserved region was predicted as the aminotransferase class-I PLP attachment site. The ATP/GTP binding motif is boxed as dotted line. Sequences were retrieved from GenBank and aligned with Clustal X (version 1.83) acetate buffer. A significant peak with a molecular weight of approximately $760 \mathrm{kDa}$ was demonstrated (Fig. 4) and suggested that Asd exists with a dodecameric structure. When Asd was eluted in phosphate buffer ( $\mathrm{pH}$ 6.0), a small peak was observed and calibrated as Asd dimer. As the $\mathrm{pH}$ kept on rising, more Asd was present in the homodimeric form at $\mathrm{pH} 7.0$ than at $\mathrm{pH} 6.0$ even though most of them still existed in the dodecameric form. The same phenomenon was also observed from the FPLC analysis, and dimers were quantified to shift from $2.5 \%$ (at $\mathrm{pH} 6.0$ ) of the total protein to $4.4 \%$ (at $\mathrm{pH} 7.0$ ). Peaks of the calculated dimer and dodecamer were both collected and verified as Asd by the Western blot analysis (Fig. 4).

Effects of temperature and $\mathrm{pH}$ on the recombinant Asd

The optimum temperature for Asd activity was at $45{ }^{\circ} \mathrm{C}$ (Fig. 5a). The enzyme exhibited at least half of its maximum activity at temperatures between 30 and $50{ }^{\circ} \mathrm{C}$, and less than $20 \%$ at $60{ }^{\circ} \mathrm{C}$. The recombinant enzyme was stable at temperatures below $40{ }^{\circ} \mathrm{C}$. As shown in Fig. 5 b, Asd maintained $80 \%$ of its activity after $1 \mathrm{~h}$ of incubation at $50{ }^{\circ} \mathrm{C}$, but nearly lost all of it at $60{ }^{\circ} \mathrm{C}$. 


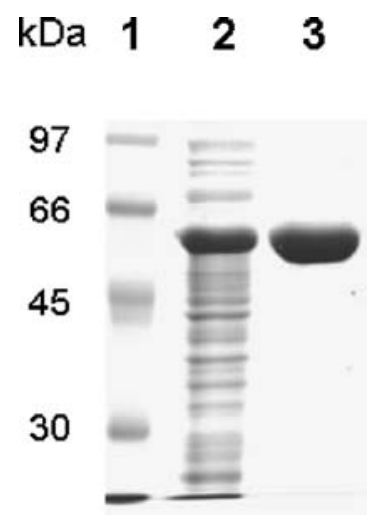

Fig. 3 SDS-PAGE (10\% polyacrylamide) of recombinant Asd from Pseudomonas sp. ATCC 19121. Asd overproduced by E. coli BL21 (DE3)pLysS/pES1 transformant was purified using the HiTrap Chelating column. Lane 1 molecular weight marker, lane 2 crude enzyme extract ( $40 \mu \mathrm{g}$ protein), lane 3 purified Asd (10 $\mu \mathrm{g}$ protein). Proteins were stained with Coomassie blue R-250

Figure $5 \mathrm{c}$ plots the $\mathrm{pH}$-dependence of recombinant Asd at $37{ }^{\circ} \mathrm{C}$. The activity was maximum at $\mathrm{pH} 5.0$ in the acetate buffer. Moreover, to measure its $\mathrm{pH}$ stability in various buffers, the purified Asd was maintained at $4{ }^{\circ} \mathrm{C}$ for 1 day. Figure $5 \mathrm{~d}$ shows that the purified Asd was fully stable at $\mathrm{pH} 4.0-8.5$.

Effect of metal ions and reagents

The activity of recombinant Asd was strongly inhibited by $10 \mathrm{mM} \mathrm{Co}^{2+}, \mathrm{Cu}^{2+}, \mathrm{Fe}^{2+}, \mathrm{Mn}^{2+}, \mathrm{Ni}^{2+}$, and $\mathrm{Zn}^{2+}$ (Table 2) to below $10 \%$ of the residual value, while the presence of $1 \mathrm{mM} \mathrm{Hg}^{2+}$ in the reaction mixture decreased the enzyme activity to an undetectable level. Zinc ions in $0.1 \mathrm{mM}$ reduced the Asd activity by approximately 5\% while

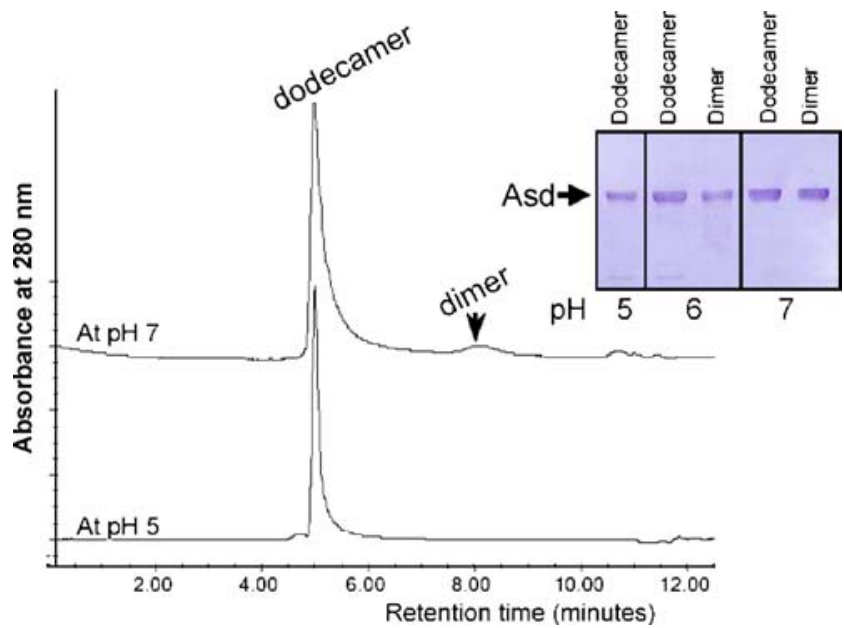

Fig. 4 HPLC gel-filtration chromatographic analyses of the recombinant Asd. Recombinant Asd incubated in acetate buffer ( $\mathrm{pH}$ 5.0) was stored at $4{ }^{\circ} \mathrm{C}$ for $2 \mathrm{~h}$. Profiles of the enzyme elution at $\mathrm{pH}$ of 5.0 and 7.0 are labeled. Each peak depicted as dodecamer and dimer, which collected during elution, was proved to be Asd through Western analysis
$10 \mathrm{mM} \mathrm{Ca}^{2+}$ reduced it by $14 \% . \mathrm{Mg}^{2+}$ ions moderately inhibited the Asd activity at $64 \%$. All the added metal ions suppressed the recombinant Asd activity, while 10 20 mM EDTA improved the enzyme activity by $10 \%$. The presence of $1 \mathrm{mM}$ of the reducing agent DTT or 2-mercaptoethanol increased the Asd activity by $7 \%$.

Kinetics and substrate as well as reaction specificity of the recombinant Asd

Using L-aspartate as the substrate for the purified recombinant Asd, the $K_{\mathrm{m}}$ value in $\beta$-decarboxylation reaction was estimated at $11.50 \mathrm{mM}$ using detection method a. The maximum velocity was $0.11 \mathrm{mM} / \mathrm{min}$ at $\mathrm{pH} 6.8$ in $10 \mathrm{mM}$ phosphate buffer containing $0.2 \mathrm{mM}$ PLP. Although Asd is highly specific to the $\beta$-decarboxylation of L-aspartate, we tried to examine its $\beta$-elimination ability towards other amino acids. In the present study, various kinds of amino acids such as those described in the "Materials and methods" section of the aminotransferase assay were used to perform enzyme reactions independently in the presence of $\alpha$-ketoglutarate at $\mathrm{pH}$ 5.0. A tiny quantity of the eliminated product was examined by detection method $\mathrm{c}$ with a specific activity of $0.128 \mathrm{U} / \mathrm{mg}$ when L-asparagine was used as substrate. When the substrate was changed to D-aspartate or L-lysine, one quarter of the product was generated when compared to the reaction of L-asparagine. During the tests with L-glutamate and L-glutamine, a very small amount of the elimination product was detected (Table 3).

The recombinant Asd also displayed aminotransferase activity, as shown in Table 3. The amino group could be transferred from either L-aspartate or $\mathrm{D}$-aspartate to $\alpha$ ketoglutarate under the Asd catalysis and produced glutamate with specific activities of 0.113 and $0.042 \mathrm{U} / \mathrm{mg}$, respectively. With about 26 and $22 \%$ of the former and the latter specific activities, respectively, pyruvate was also a good amino acceptor when the amino acids were Lglutamine and L-glutamate. Under the same conditions, no transamination reaction of the tested amino acids was observed when oxaloacetate served as the amino group acceptor.

\section{Discussion}

The present work demonstrated the asd cluster from Pseudomonas sp. ATCC 19121, and presumably encoded three enzymes involved in the amino acid metabolism and the two membrane proteins. In the present study, asd is located $55 \mathrm{bp}$ downstream of the probable aspartate-alanine antiporter gene, and oriented contrary to the asp operon in the Tetragenococcus halophila reported by Abe et al. 
Fig. 5 Effect of $\mathrm{pH}$ and temperature on Asd activity and stability. a Optimal temperature of Asd reaction, $\mathbf{b}$ thermal stability of the recombinant Asd, c optimal $\mathrm{pH}$ for Asd reaction, and $\mathbf{d} \mathrm{pH}$ stability of the recombinant Asd. Reaction conditions were as described in "Materials and methods" section
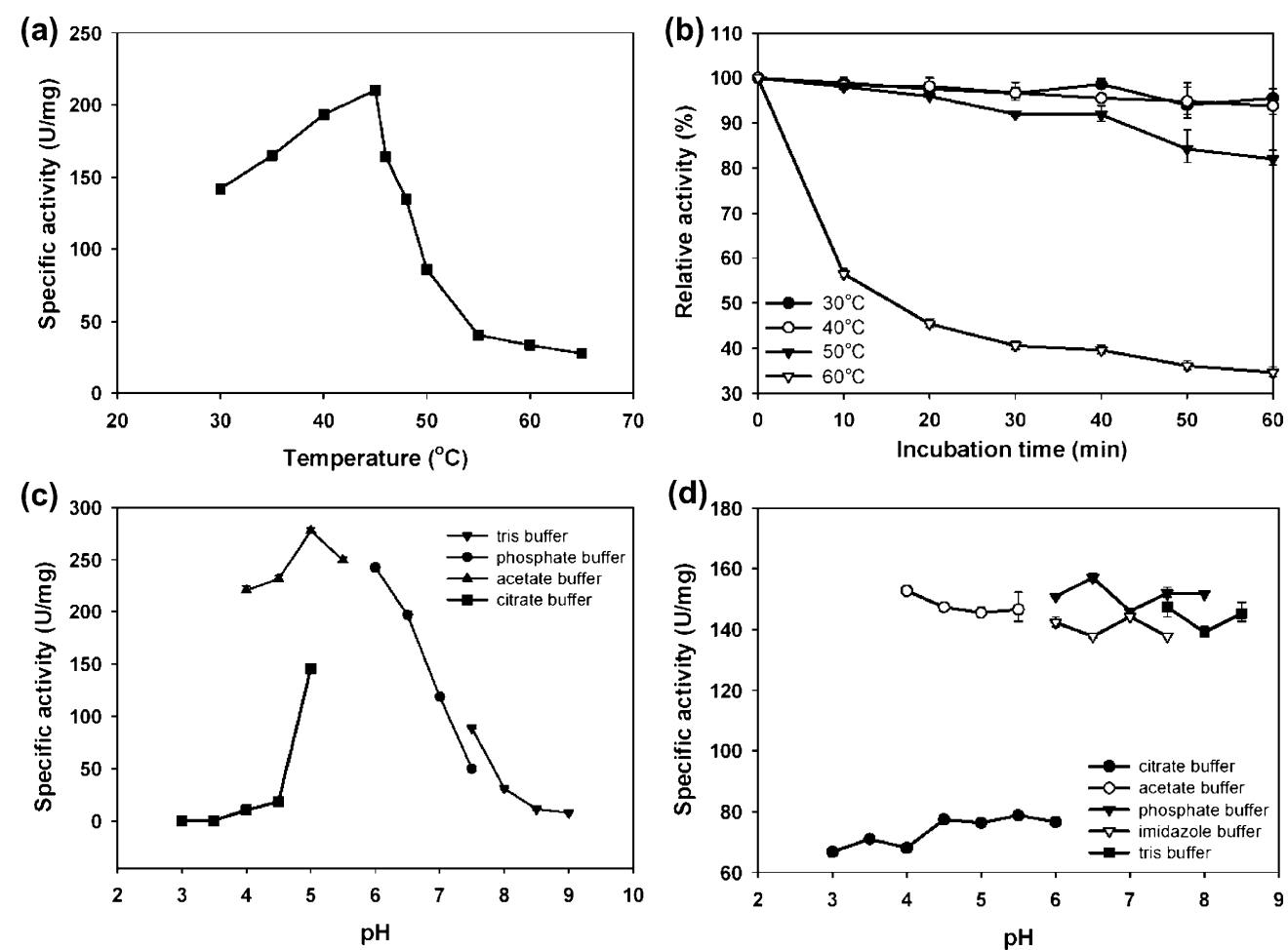

(2002). Its RBS sequence is found 7 bp upstream of the ATG initiation codon. Combining the actions of the Asd and the antiporter was supposed to establish an electrochemical proton gradient and thereby exploited for ATP

Table 2 Effect of divalent cations and various reagents on the recombinant Asd activity

\begin{tabular}{lcc}
\hline Reagents & Conc. $(\mathrm{mM})$ & Relative $^{2}$ \\
\hline None & - & 100 \\
$\mathrm{Ca}^{2+}$ & 10 & 86.1 \\
$\mathrm{Co}^{2+}$ & 10 & 6.9 \\
$\mathrm{Cu}^{2+}$ & 0.1 & 20.3 \\
& 10 & 0.5 \\
$\mathrm{Fe}^{2+}$ & 0.1 & 72.1 \\
& 10 & 7.4 \\
$\mathrm{Hg}^{2+}$ & 1 & 0.0 \\
$\mathrm{Mg}^{2+}$ & 10 & 64.0 \\
$\mathrm{Mn}^{2+}$ & 10 & 7.8 \\
$\mathrm{Ni}^{2+}$ & 10 & 8.4 \\
$\mathrm{Zn}^{2+}$ & 0.1 & 94.9 \\
& 10 & 7.7 \\
EDTA $^{\mathrm{b}}$ & 10 & 110.9 \\
& 20 & 111.3 \\
2-Mercaptoethanol & 1 & 107.1 \\
& 2 & 101.1 \\
DTT $^{\mathrm{c}}$ & 1 & 107.4 \\
& 10 & 105.2 \\
\hline
\end{tabular}

${ }^{a}$ Values shown are the means of duplicate determinations with a standard deviation of less than $20 \%$

${ }^{\mathrm{b}}$ EDTA, ethylenedinitrilotetraacetic acid

${ }^{\mathrm{c}}$ DTT, dithiothreitol synthesis by $\mathrm{H}^{+}$-coupled $\mathrm{F}_{1} \mathrm{~F}_{0} \mathrm{ATP}$ synthases (Dimroth and Schink 1998). Meanwhile, an ATP/GTP binding motif was observed in the Asd sequence, and the aspartate $\beta$-decarboxylation was supposed to contribute to the conservation of energy in the studied Pseudomonas strain being studied. The other two genes of potential interest are the $i l v D$ (dihydroxy-acid dehydratase) and the $d g d R(2,2-$ dialkylglycine decarboxylase repressor protein). The former dehydrates dihydroxy acids in the biosynthesis of L-valine and L-isoleucine from pyruvate and threonine, respectively, while the latter regulates the expression of the $d g d$ gene and suppresses the generation of L-alanine and $\mathrm{CO}_{2}$ from pyruvate and 2,2-dialkyglycine. DgdR influences the enzymatic production of L-alanine. Because it is the same product as the $\beta$-decarboxylation of aspartate, Asd was assumed to cooperate with the DgdR control in vivo. All genes in the asd cluster from Pseudomonas sp. were supposed to be involved in the metabolic pathways of pyruvate and aspartate families.

Considerable percentage of identities, $84 \%$ for the gene and $93 \%$ for the amino acid sequence, were exhibited between Asds from A. faecalis and P. dacunhae. However, based on the phylogenetic analysis (Fig. 1), a lower percentage of identity of the Asd was observed between Pseudomonas sp. and $P$. dacunhae (Table 1) from the same genus-Pseudomonas. This suggested that Asd from $P$. dacunhae is more closely related to enzyme evolution of $A$. faecalis than to that of Pseudomonas sp. ATCC 19121. Moreover, the GC content of asd from Pseudomonas sp. ATCC 19121 and $P$. dacunhae were found to be 65.4 and $56 \%$, respectively. 
Table 3 Substrate specificity of the recombinant Asd on $\beta$-elimination and transamination activity

\begin{tabular}{lllr}
\hline Substrate $^{\mathrm{a}}$ & Keto acid & Specific activity $(\mathrm{U} / \mathrm{mg})$ & Relative activity $^{\mathrm{b}}(\%)$ \\
\hline$\beta$-Elimination & & & 100.0 \\
L-Asparagine & $\alpha$-Ketoglutarate & 0.128 & 25.1 \\
D-Aspartate & $\alpha$-Ketoglutarate & 0.032 & 21.7 \\
L-Lysine & $\alpha$-Ketoglutarate & 0.028 & 10.7 \\
L-Glutamine & $\alpha$-Ketoglutarate & 0.014 & 6.8 \\
L-Glutamate & $\alpha$-Ketoglutarate & 0.009 & 100.0 \\
Transamination & & & 37.6 \\
L-Aspartate & $\alpha$-Ketoglutarate & 0.113 & 26.4 \\
D-Aspartate & $\alpha$-Ketoglutarate & 0.042 & 22.1 \\
L-Glutamine & Pyruvate & 0.030 & 13.2 \\
L-Glutamate & Pyruvate & 0.025 & 0.015 \\
L-Alanine & $\alpha$-Ketoglutarate & & \\
\hline
\end{tabular}

${ }^{a}$ In addition to the data listed above, no reaction product could be detected when using other tested amino acids as the substrate

${ }^{b}$ Detection method $\mathrm{c}$ is too sensitive to correctly quantify the excess alanine produced in the $\beta$-decarboxylation reaction of $\mathrm{L}$-aspartate when $\alpha$-ketoglutarate exists. Therefore, the reaction of L-asparagine that can be well quantified as that of the highest level was defined to be $100 \%$ in the $\beta$-elimination reaction. As for the transamination reaction, the specific activity between L-aspartate and $\alpha$-ketoglutarate was defined to be $100 \%$

These differences in both the GC content and sequence identities of Asd were probably due to the genetic diversity of Pseudomonas (Dogan and Boor 2003).

Like other microbial Asds, our His-tagged recombinant Asd has similar optimal $\mathrm{pH}$ values and optimal reaction temperatures. Furthermore, the $\mathrm{pH}$ stability results (Fig. 5d) in the present study suggested that the enzyme is stable over a broad $\mathrm{pH}$ range. Based on the gel-filtration profiles (Fig. 4), majority $(>95 \%)$ of recombinant Asd exhibited the dodecameric form as the $\mathrm{pH}$ shifted from 5.0 to 7.0. A similar phenomenon was previously observed in the sedimentation equilibrium test for purified wild-type Asd from $A$. faecalis by Bowers et al. 1970. To identify the electron microscopic appearance of the recombinant Asd, we found the dodecameric holoenzyme to be very similar to the widetype Asds from $P$. dacunhae (Tate and Meister 1970) and $A$. faecalis (Bowers et al. 1970) at pH 5.0 (data not shown).

The effect of metal ions on pure Asd has never been reported. However, El-Rahmany found that $\mathrm{Mn}^{2+}, \mathrm{Ni}^{2+}$, $\mathrm{Co}^{2+}$, and $\mathrm{Fe}^{2+}$ (all in $10 \mathrm{mM}$ ) enhanced the Asd activity by 20-38\%, while $10 \mathrm{mM}$ EDTA reduced it by $62 \%$ in cellfree extracts of Cunninghamella elegans and Penicillium citrinum (El-Rahmany 1994). In the present investigation, the purified recombinant Asd was dialyzed as described in the "Materials and methods" section. Because metal ions could inhibit the coupled L-amino acid oxidase reaction and bias the quantification of Asd product, L-alanines were analyzed by HPLC. All metal ions examined herein inhibited the Asd activity, while the four metal ions mentioned earlier did not increase but inhibit the Asd activity by up to $90 \%$.

In the present study, the recombinant Asd $\beta$ eliminated L-aspargine in detectable amounts. L-Aspartate was still the best substrate for the $\beta$-decarboxylation reaction with a specific activity of about 2,187-fold. While D-aspartate served as the substrate in the presence of $\alpha$-ketoglutarate in the Asd catalyzed reaction mixture, a little amount of both alanine produced by $\beta$-decarboxylation and glutamate produced by transamination, were determined. As compared to the reaction between L-aspartate and $\alpha$-ketoglutarate, L-aspartate was $\beta$-decarboxylated 8,715 times more and transaminated 2.7 times more than the D-aspartate under the catalyzation of the recombinant Asd. It suggested that the Asd recombinant protein is not strongly stereospecific for L-amino acids in the transamination reaction.

Altering the reaction specificity of PLP-dependent enzyme by point mutations has attracted some interest in recent times. Few asd sequences were cloned until recently, and the consequent lack of asd sequence information has retarded the progress in elucidating the structural relationship between Asd and aminotransferase. In Fig. 2, residues marked as black squares correspond to the three residues mutated in aspartate aminotransferase, based on the molecular modeling of the partial Asd structure and using tyrosine aminotransferase as template (3tat in Protein Data Bank). Asd residues, which were supposed to interact with $\alpha$ - and $\beta$-carboxyl groups of the substrate, L-aspartate, and the O-3' of cofactor PLP were the same as those mutated in aspartate aminotransferase. Therefore, we have proposed that these three residues could not be the only key determinants in enzyme catalysis.

In summary, an asd cluster involved in the metabolic pathway of aspartate families was cloned in the present study. Moreover, biochemical characterization and reaction specificity studies of the recombinant Asd led to interest in the protein structure of the holoenzyme. Because no Asd structure has yet been determined, the authors are currently undertaking the analysis of X-ray diffraction data from this 
recombinant Asd. From these results, we expect that amino acid residues governing the pathway of the reaction intermediates could be identified in the near future.

Acknowledgements This work was supported by grants 90AS2.1.1-FD-Z4(1) and 91AS-3.1.1-FD-Z5(3) from the Council of Agriculture, and was partially supported by grant NSC92-2313-B002-092 and NSC94-2313-B-002-049 from the National Science Council, Taipei, Taiwan.

\section{References}

Abe K, Ohnishi F, Yagi K, Nakajima T, Higuchi T, Sano M, Machida M, Sarker RI, Maloney PC (2002) Plasmid-encoded asp operon confers a proton motive metabolic cycle catalyzed by an aspartate-alanine exchange reaction. J Bacteriol 184:2906-2913

Altschul SF, Madden TL, Schaffer AA, Zhang J, Zhang Z, Miller W, Lipman DJ (1997) Gapped BLAST and PSI-BLAST: a new generation of protein database search programs. Nucleic Acids Res 25:3389-3402

Bowers WF, Czubaroff VB, Haschemeyer RH (1970) Subunit structure of L-aspartate $\beta$-decarboxylase from Alcaligenes faecalis. Biochemistry 9:2620-2625

Bradford MM (1976) A rapid and sensitive method for the quantitation of microgram quantities of protein utilizing the principle of protein-dye binding. Anal Biochem 72:248-254

Chen CC, Chou TL, Lee CY (2000) Cloning, expression and characterization of L-aspartate $\beta$-decarboxylase gene from Alcaligenes faecalis CCRC 11585. J Ind Microbiol 25:132-140

Chibata I, Kakimoto T, Kato J (1965) Enzymatic production of L-alanine by Pseudomonas dacunhae. Appl Microbiol 13: 638-645

Crawford LV (1958) Studies on the aspartic decarboxylase of Nocardia globerula. Biochem J 68:221-225

Dimroth P, Schink B (1998) Energy conservation in the decarboxylation of dicarboxylic acids by fermenting bacteria. Arch Microbiol 170:69-77
Dogan B, Boor KJ (2003) Genetic diversity and spoilage potentials among Pseudomonas spp. isolated from fluid milk products and dairy processing plants. Appl Environ Microbiol 69:130-138

Dunathan HC (1966) Conformation and reaction specificity in pyridoxal phosphate enzymes. Proc Natl Acad Sci USA 55:712-716

El-Rahmany TA (1994) Comparison of L-aspartate 4-carboxy-lyases of Cunninghamella elegans and Penicillium citrinum. Microbiol Res 149:253-257

Graber R, Kasper P, Malashkevich VN, Strop P, Gehring H, Jansonius JN, Christen P (1999) Conversion of aspartate aminotransferase into an L-aspartate $\beta$-decarboxylase by a triple active-site mutation. J Biol Chem 274:31203-31208

Laemmli UK (1970) Cleavage of structural proteins during the assembly of the head of bacteriophage T4. Nature 227:680-685

Nishimura JS, Manning JM, Meister A (1962) Studies on the mechanism of activation of aspartic acid $\beta$-decarboxylase by $\alpha$ keto acids and pyridoxal 5'-phosphate. Biochemistry 1:442-447

Novogrodsky A, Nishimura JS, Meister A (1963) Transamination and $\beta$-decarboxylation of aspartate catalyzed by the same pyridoxal phosphate-enzyme. J Biol Chem 238:PC1903-PC1905

Rathod PK, Fellman JH (1985) Identification of mammalian aspartate4-decarboxylase. Arch Biochem Biophys 238:435-446

Rozzell JD (1991) Method and compositions for the production of Lalanine and derivatives. US Patent No. 5,019,509

Saitou N, Nei M (1987) The neighbor-joining method: a new method for reconstructing phylogenetic trees. Mol Biol Evol 4: 406-425

Sambrook J, Fritsch EF, Manniatis T (1989) Molecular cloning: a laboratory manual. Cold Spring Harbor Laboratory Press, New York

Tate ST, Meister A (1970) Regulation and subunit structure of aspartate $\beta$-decarboxylase. Studies on the enzymes from Alcaligenes faecalis and Pseudomonas dacunhae. Biochemistry 9:2626-2632

Thompson JD, Gibson TJ, Plewniak F, Jeanmougin F, Higgins DG (1997) The ClustalX windows interface: flexible strategies for multiple sequence alignment aided by quality analysis tools. Nucleic Acids Res 25:4876-4882

Wilson EM, Kornberg HL (1963) Properties of crystalline L-aspartate 4-carboxy-lyase from Achromobacter sp. Biochem J 88:578-587 